\title{
Modul Edukasi Untuk Peningkatan Pengetahuan Orang Tua dalam Melatih Anak Cerebral Palsy di Yogyakarta
}

\author{
Education Module to Improve Knowledge of Parent's \\ in Training Children with Cerebral Palsy at \\ Yogyakarta
}

\author{
Almas Awanis ${ }^{1}$, Sevy Astriyana² \\ almasawania@gmail.com; physio.astriyana.s@stikesnas.ac.id \\ ${ }^{12}$ Program Studi DIV Fisioterapi, STIKES Nasional, Surakarta
}

\begin{abstract}
Abstrak
Di Indonesia anak dengan gangguan Cerebral Palsy (CP) digolongkan ke dalam kelompok Anak Berkebutuhan Khusus (ABK) dengan prevalensi kejadian rendah. Dari prevalensi kejadian yang rendah bukan berarti tanpa masalah bagi orang tua dalam mengurus anak CP. Dukungan terhadap anak berkebutuhan khusus dibuktikan dengan ditetapkan Yogyakarta sebagai Kota Layak Anak (KLA) pada Tahun 2016. Tetapi, pada kenyataannya pada studi pendahuluan yang dilakukan didapat masih jarangnya program latihan yang dilakukan kembali di rumah yang mendukung tercapainya program latihan bagi anak berkebutuhan khusus, sehingga perlu adanya pemberian edukasi berupa modul yang bisa membantu orang tua dalam melatih anak mereka yang menderita Cerebral Palsy (CP). Penelitian ini merupakan jenis penelitian kuantitatif dengan rancangan one group pre and post test design. Penelitian dilakukan pada 40 orang tua yang mendampingi anak dengan gangguan CP saat terapi di Rehabilitasi Medik RSA UGM, RSUD Yogyakarta dan komunitas Wahana Keluarga Cerebral Palsy (WKCP). Analisa bivariabel menggunakan Paired T-Test untuk mengetahui bagaimana perbedaan pengaruh saat sebelum diberikan modul dan setelah diberikan modul edukasi. Analisa bivariabel menunjukan adanya pengaruh pemberian modul edukasi untuk peningkatan pengetahuan dengan selisih mean $1,6(p<0,001)$. Hasil penelitian menunjukan bahwa terdapat peningkatan pengetahuan orang tua dari pemberian edukasi dalam melatih anak cerebral palsy di rumah.
\end{abstract}

Kata Kunci : Edukasi, Pengetahuan, Latihan Fisik, Cerebral Palsy

\begin{abstract}
In Indonesia, children with cerebral palsy (CP) are classified into groups of Children whit special needs with a low prevalence of occurance. From the prefalence of low incidence does not mean without problems for parents in taking care of children with cerebral palsy. Support for children with special needs is proven by Yogyakarta being designated as a Child-Friendly City in 2016. However, in the preliminary study carried out there was still a rare exercise program carryout at home for supporting the achievement of training program for children with cerebral palsy. So, there needs to be education in form of modules that can help parent do the home program of exercise. This research was quantitative research with one group pre and posttest design. The study was conducted on Forty parents
\end{abstract}


(biological relatives or babysitters) who accompanied children with $C P$ sisorders during therapy session at the Rehabilitasi Medik RSA UGM, RSUD Yogyakarta and Wahana Keluarga Cerebral Palsy (WKCP) community. Bivariable analysis uses the paired t-test to find out the differenceinfluence before and after being given an educational module. Bivariable analysis showed that have an influence of education module distribution on the improvement of competence with the mean difference of $1.6(p<0,001)$. The result showed was an increase in parental knowledge of providing education module to perform home program for their children with cerebral palsy disorders.

Keywords : Education, Knowledge, Physical Exercise, Cerebral Palsy

\section{Pendahuluan}

Di Indonesia anak dengan cerebral palsy (CP) digolongkan kedalam Anak Berkebutuhan Khusus (ABK) yang mana angka kejadiannya memang rendah. RISKESDAS di tahun 2010 menunjukan kejadian anak dengan cerebral palsy sebesar 9\% diantara prevalensi anak dengan gangguan. Ditambah lagi pada tahun 2016 di Daerah Istimewa Yogyakarta telah ditetapkan menjadi Kota Layak Anak (KLA) yang tertuang di dalam Peraturan Daerah (Perda) No.1 Tahun 2016. Dengan adanya KLA maka anak normal maupun anak disabilitas seperti anak CP memiliki hak yang wajib dijamin, dilindungi dan dipenuhi oleh orang tua, keluarga, masyarakat, pemerintah dan Negara yang dapat mendukung anak. Faktor eksternal seperti lingkungan keluarga, komunitas, dan pemerintah sebagai pengambil kebijakan menjadi bagian yang mendukung anak CP untuk dapat meningkatkan kemandirian fungsional mereka (Posłuszny et al., 2016). Penanganan anak CP ini tidak lepas pula dari faktor internal dan faktor eksternal yang mengarah pada pemberian program latihan. Kesesuaian antar kedua faktor benar-benar harus dicapai oleh orang tua sebagai lingkungan terdekat anak. Beberapa penelitian menyebutkan bahwa pengaruh lingkungan keluarga terhadap anak CP mendukung terciptanya kualitas hidup mereka, karena keseharian anak lebih dekat dengan keluarga atau orang tua (Anaby et al., 2013, Chen et al., 2014, Chiarello et al., 2016, Chien et al., 2017, Kang et al., 2014, Palisano et al., 2012). Namun, pada penelitian Harumi et al., (2017) menyebutkan bahwa orang tua belum berperan banyak untuk penanganan anak CP. Hal ini terlihat dari masih jarangnya program latihan yang dilakukan kembali ketika di rumah karena keterbatasan pengetahuan dari pihak orang tua serta kurang mengakses informasi mengenai anak CP.

Kurangnya peran orang tua inilah yang kemudian membuat penulis tertarik untuk memberikan modul edukasi untuk peningkatan pengetahuan orang tua dalam melatih anak cerebral palsy. Modul yang diberikan ini diharapkan mampu mambantu memfasilitasi orang tua saat di rumah dalam melakukan sesi pengulangan latihan sendiri. Mengingat bahwa waktu yang lebih lama dihabiskan anak CP adalah di rumah, dibandingkan dengan tempat mereka terapi.

Keterampilan orang tua dalam mempraktikkan isi modul ini di rumah juga di imbangi dengan proses diskusi saat masa penelitian berlangsung. Kendala segala informasi yang orang tua hadapi saat mempraktikkan isi modul edukasi akan dijelaskan saat sesi pertemuan dengan peneliti.

\section{Metode Penelitian}

\section{Alat Penelitian}

Alat yang digunakan dalam penelitian ini adalah modul edukasi yang penulis buat dari beberapa literatur dan dilakukan uji validitas serta reliabilitas, kuesioner skala pengetahuan, lembar Gross Motor Function Classification System (GMFCS) dan Hollingshead index two factor.

\section{Bahan Penelitian}

Tidak ada bahan yang digunakan dalam penelitian ini.

\section{Jenis dan Rancangan Penelitian}

Jenis penelitian yang digunakan adalah kuantitatif dengan rancangan one group pre and post test design. 


\section{Populasi dan Sampel}

Populasi dalam penelitian ini adalah seluruh orang tua yang melakukan sesi terapi rehabilitasi medis di Rumah Sakit Akademik UGM, Rumah Sakit Umum Daerah (RSUD) Yogyakarta dan komunitas Wahana Keluarga Cerebral Palsy (WKCP). Populasi yang didapatkan sebanyak 56 orang dengan kriteria inklusi yang terdiri dari (1) tinggal satu rumah dengan anak $\mathrm{CP}$, (2) terlibat langsung dalam mengurus anak CP, (3) bertempat tinggal di Yogyakarta, (4) Terjangkau untuk mengakses pelayanan rehabilitasi medis, (5) bersedia untuk menjadi responden dan kriteria eksklusi yang terdiri dari (1) orang tua yang mengantar anaknya ke terapi rehabilitasi medis kurang dari 3 bulan, (2) Anak cerebral palsy yang telah memiliki kemampuan berjalan secara mandiri, (3) dalam waktu dekat akan pergi lama meninggalkan Yogyakarta.

Perhitungan besar sampel pada penelitian ini didapatkan sebanyak 40 responden. Penelitian dimulai sejak Etical Clearance diterbitkan oleh Fakultas Kedokteran, Kesehatan Masyarakat dan Keperawatan, Universitas Gadjah Mada yakni pada tanggal 2 April 2018 dengan nomor Ref: KE/FK/0285/EC/2018.

\section{Analisa Data}

Analisis Univariable dilakukan bertujuan untuk mengetahui bagaimana sebaran karakteristik responden yang diteliti serta deskripsi dari masing-masing variabel akan ditampilan dalam bentuk tabel dan grafik. Analisis Bivariable dilakukan untuk mengetahui apakah ada pengaruh pemberian modul edukasi untuk peningkatan pengetahuan orang tua dalam melatih anak cerebral palsy di rumah. Uji yang digunakan adalah Paired T-Test. Analisis bivariabel berikutnya adalah menganalisis rata-rata perubahan pengetahuan di antara variabel luar yang terdiri dari jenis kelamin, usia, fungsi motorik anak $\mathrm{CP}$ dan, status sosial ekonomi.

\section{Hasil dan Pembahasan}

Karakteristik responden yang masuk kedalam penelitian terlihat seperti tabel di bawah ini.
Tabel I. Karakteristik Responden.

\begin{tabular}{lcc}
\hline \multicolumn{1}{c}{ Variabel } & $\begin{array}{c}\text { Frekuansi } \\
(\mathbf{n})\end{array}$ & $\begin{array}{c}\text { Persentase } \\
\text { (\%) }\end{array}$ \\
\hline Status Pendamping & & \\
Anak CP & & \\
Orang Tua Kandung & 39 & 97.50 \\
Pengasuh & 1 & 2.50 \\
\hline Status Sosial Ekonomi & & \\
(SSE) & & \\
Rendah & 31 & 77.50 \\
Tinggi & 9 & 2.50 \\
\hline Jenis Kelamin CP & & \\
Laki-laki & 23 & 57.50 \\
Perempuan & 17 & 42.50 \\
\hline Rentang Usia CP & & \\
< 2 tahun & 0 & 0 \\
2-4 tahun & 8 & 20 \\
4-6 tahun & 6 & 15 \\
6-12 tahun & 14 & 35 \\
12-18 tahun & 12 & 30 \\
\hline Derajat keparahan & & \\
gangguan motorik kasar & & \\
Derajat 5 & 0 & 0 \\
Derajat 4 & 20 & 50 \\
Derajat 3 & 14 & 35 \\
Derajat 2 & 4 & 10 \\
Derajat 1 & 2 & 5 \\
\hline
\end{tabular}

Tabel I menunjukkan bahwa karakteristik keluarga yang mendampingi anak CP saat terapi adalah orang tua kandung dengan Status Sosial Ekonomi (SSE) rendah. Karakteristik jenis kelamin anak CP yang didampingi sebagian besar berjenis kelamin laki-laki berusia 6-12 tahun dengan derajat keparahan gangguan motorik kasar anak CP, sebagian besar derajat 4 . Derajat 4 disini tingkat keparahan yang dialami anak CP yakni kontrol kepala belum baik, namun gerakan seperti berguling atau merayap sudah mulai ada pada anak.

Tingkat pengetahuan orang tua sebelum dan sesudah mendapatkan modul terlihat seperti pada Gambar 1 . 


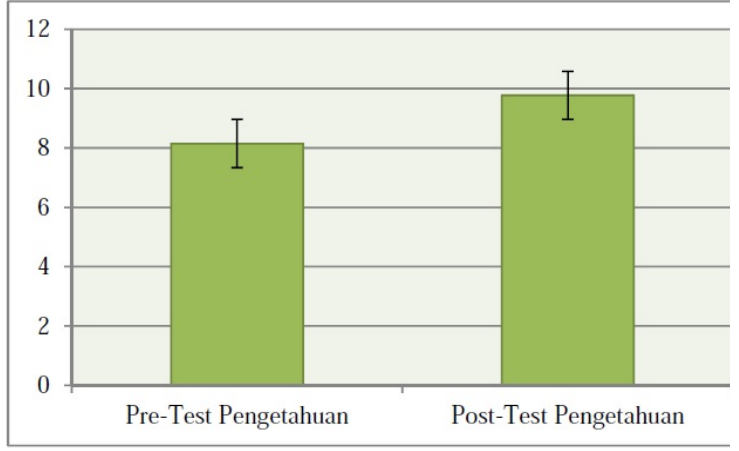

Gambar 1. Perubahan mean pengetahuan orang tua

Tabel II. Hasil pre dan post test pengetahuan orang tua

\begin{tabular}{lcccc}
\hline \multicolumn{1}{c}{ Variabel } & Mean & $\begin{array}{c}\text { Standar } \\
\text { Deviasi }\end{array}$ & $\begin{array}{c}\text { Selisih } \\
\text { Mean }\end{array}$ & $p$-value \\
\cline { 1 - 3 } $\begin{array}{l}\text { Pre test } \\
\text { pengetahuan }\end{array}$ & 8,15 & 2,17 & & \\
\cline { 1 - 2 } $\begin{array}{l}\text { Post test } \\
\text { pengetahuan }\end{array}$ & 9,77 & 1,09 & 1,62 & $<0,001$ \\
\hline
\end{tabular}

Pada Gambar 1 merupakan visualisasi data lengkap dengan uji perbandingan nilai rata-rata pengetahuan orang tua. Terlihat bahwa mean atau nilai dari rata-rata pengetahuan orang tua mengalami peningkatan sebanyak 1,62 (Tabel II) dari yang awalnya saat pre-test didapatkan rata-rata yang benar menjawab soal sebanyak 8 soal. Kemudian setelah diberikan intervensi dan diberikan post-test kembali didapatkan mean meningkat menjadi 9,775 atau sebanyak 10 soal orang tua dapat menjawab benar, dari 11 pertanyaan yang tersedia. Nilai probabilitas secara statistik hasil analisis ini adalah $\mathrm{p}<0,001$ sehingga disimpulkan bahwa peningkatan mean pengetahuan sangat signifikan.

Hasil analisa secara statistik yang telah dilakukan terlihat bahwa memang terdapat peningkatan nilai rata-rata pengetahuan dari orang tua saat sebelum mendapatkan modul edukasi dibandingkan dengan saat setelah mendapatkan modul edukasi. Namun tidak hanya secara statistik saja, secara klinis adanya peningkatan nilai rata-rata dari 8 menjadi 10 disimpulkan bermakna. Khoiron (2014) menyatakan bahwa dengan peningkatan pengetahuan sebanyak $13 \%$ saja secara klinisi dikatakan peningkatan ini bermakna. Pada capaian penelitian ini sebanyak $18 \%$, sehingga terbukti bahwa memang modul ini berpengaruh untuk orang tua.

Aspek terpenting dari pemberian edukasi ini adalah materi yang sesuai untuk pengetahuan orang tua dalam memahami anak cerebral palsy. Saat pelaksanaan penelitian, isi materi dari modul memang harus disesuaikan dengan kebutuhan edukasi dari peserta yang mengikuti, karena hal ini akan mempengaruhi terjadinya keberhasilan proses transfer informasi. Antusiasme peserta terhadap materi juga terlihat saat pertemuan di minggu kedua setelah mereka membawa modul ke rumah. Orang tua mulai mempersiapkan pertanyaan untuk didiskusikan pada pertemuan berikutnya, seperti pertanyaan tentang menganalisa kemampuan motorik kasar anak dengan tools Gross Motor Function Classification System (GMFCS). Dari antusiasme inilah mereka dapat termotivasi membahas topik yang ada di modul tersebut (Pareira et al., 2018).

Adanya proses diskusi maka pengetahuan dari orang tua dapat meningkat. Melalui proses pemberian edukasi berupa modul inilah orang tua dapat membawa modul ke rumah dan mengulangi beberapa gerakan di rumah sehingga mereka paham program seperti apa yang bisa dikerjakan. Ketika ada hambatan yang dialami saat di rumah, maka diskusi saat pertemuan bisa menjadi solusi. Dengan mengulangi membaca modul terus menerus inilah yang kemudian berdampak pada peningkatan pengetahuan (Fatmawati, 2016).

Pemberian edukasi berupa modul juga bisa mengurangi lupa pada ingatan akan suatu obyek. Dalam penelitian Patriani et al. (2010) yang membahas tentang teori low disuse, ia memaparkan bahwa kejadian lupa bukanlah disebabkan karena lamanya waktu akan suatu peristiwa, namun seberapa sering informasi yang didapatkan diulang kembali, dalam hal ini adalah pemberian terapi fisik oleh fisioterapi lalu meminta orang tua mengulanginya kembali di rumah. Dengan adanya modul maka gerakan yang diajarkan bisa diulang kembali.

Faktor lain seperti faktor sosial, ekonomi, dan budaya seperti ibu tidak bekerja, dapat mengatur waktunya secara fleksibel untuk membaca modul, dan menerapkan pada anak dirumah. Hasil yang 
didapat berdasarkan sumber data primer juga diketahui bahwa sebagian orang tua berstatus sosial ekonomi rendah dikarenakan sebagian besar ibu adalah seorang pekerja rumah tangga biasa. Ibu memegang peran utama pengasuhan anak, sehingga dengan waktunya yang lebih banyak di rumah maka ada usaha untuk mendapatkan informasi dalam pengasuhan anaknya yang mengalami CP (Wawan dan Dewi, 2011, Harumi et al., 2017, Rovasita, 2016).

Dari Tabel I juga terlihat bahwa orang tua dengan status sosial ekonomi yang tinggi memiliki peningkatan pengetahuan yang tinggi pula. Hal ini bisa terjadi karena orang tua mampu memilih keputusan dimana anaknya akan melakukan terapi. Teori pokok Precede dan Preceed miliknya Green et al. (1980) yang digunakan sebagai landasan teori ini juga memaparkan bahwa pengetahuan dipengaruhi oleh bagaimana pengalaman seseorang dengan lingkungannya dapat mendukung. Lingkungan seperti tempat terapi yang memberikan kegiatan pemberian edukasi untuk meningkatkan pengetahuan akan berdampak pada kepatuhan dalam rehabilitasi (Arora et al., 2014).

\section{Simpulan}

Hasil penelitian menunjukkan bahwa terdapat peningkatan pengetahuan orang tua dari pemberian modul edukasi dalam melatih anak cerebral palsy di rumah secara signifikan.

\section{Ucapan Terima Kasih}

Peneliti menyampaikan terima kasih kepada Rumah Sakit Akademi (RSA) Universitas Gadjah Mada, Rumah Sakit Umum Daerah Yogyakarta (RSUD), dan Wahana Keluarga Cerebral Palsy (WKCP) yang telah memberikan izin dan kesempatan kepada penulis untuk melakukan penelitian, serta orang tua yang mendampingi anak cerebral palsy yang bersedia menjadi responden dalam penelitian ini.

\section{Daftar Pustaka}

Anaby D, Hand C, Bradley L, DiRezze B, Forhan M, DiGiacomo A, Law M. The effect of the environment on participation of children and youth with disabilities: a scoping review. Disability and rehabilitation. 2013 Sep 1;35(19):1589-98.
Chen KL, Tseng MH, Shieh JY, Lu L, Huang CY. Determinants of quality of life in children with cerebral palsy: A comprehensive biopsychosocial approach. Research in developmental disabilities. 2014 Feb 1;35(2):520-8.

Chiarello LA, Bartlett DJ, Palisano RJ, McCoy SW, Fiss AL, Jeffries L, Wilk P. Determinants of participation in family and recreational activities of young children with cerebral palsy. Disability and rehabilitation. 2016 Dec 3;38(25):2455-68.

Chien CW, Branjerdporn G, Rodger S, Copley J. Exploring environmental restrictions on everyday life participation of children with developmental disability. Journal of Intellectual \& Developmental Disability. 2017 Jan 2;42(1):61-73.

Colver Allan, Fairhurst Charles, Pharoah Peter O. D. Cerebral palsy. The Lancet. 2014; 383: 1240-1249.

Fatmawati S, Hapsara S, Gamayanti DI. Pemberdayaan Keluarga Dalam Perawatan Diri Pada Anak Cerebral Palsy Di YogyakartA (Doctoral dissertation, Universitas Gadjah Mada).

Green LW, Kreuter MW, Deeds SG, Partridge KB, Bartlett E. (1980) Health education planning: a diagnostic approach.

Harumi L, Pamungkasari EP, Murti B. Effectiveness of Practical Integrative Module in Empowering Family Empowering Family of Children with Cerebral Palsy. Journal of Health Promotion and Behavior. 2017 Jun 11;2(2):173-82.

Kang LJ, Palisano RJ, King GA, Chiarello LA. A multidimensional model of optimal participation of children with physical disabilities. Disability and rehabilitation. 2014 Sep 1;36(20):173541.

Khoirun, N. (2014) Efektifitas Pendidikan Kesehatan dengan Menggunakan Media Leaflet dan Media Slide Power Point terhadap Perubahan Pengetahuan, Sikap, dan Perilaku Deteksi Dini Kanker Serviks pada IbuIbu PKK di Wilayah Kerja Puskesmas Kertasura Sukoharjo. Universitas Muhammadiyah Surakarta. 
Pareira, M. I. R., Patmonodewo, S. \& Saleh, A. Y. (2018) Program Pelatihan pada Ibu untuk Meningkatkan Pengetahuan Komunikasi Efektif Anak Praseklah. Jurnal RAP, 8 (2); 147-157.

Patriani AA, Paramastri I, Priyanto MA. Pemberdayaan Keluarga dalam Rehabilitasi Medik Paru pada Penderita Penyakit Paru Obstruksi Kronik di Balai Pengobatan Penyakit Paru-Paru Yogyakarta. Berita Kedokteran Masyarakat. 2010;26(2):55.

Palisano RJ, Chiarello LA, King GA, Novak I, Stoner T, Fiss A. Participation-based therapy for children with physical disabilities. Disability and rehabilitation. 2012 Jun 1;34(12):104152.

Posłuszny A, Myśliwiec A, Saulicz E, Doroniewicz I, Linek P, Wolny T. Current understanding of the factors influencing the functional independence of people with cerebral palsy: a review of the literature. International Journal of Developmental Disabilities. 2017 Apr 3;63(2):77-90.

Pountney TE, editor. Physiotherapy for children. Elsevier Health Sciences; 2007.

Rovasita, S. (2016) Pengaruh Sharing Experiences Penyandang Cerebral Palsy terhadap Resiliensi Orang Tua Anak Cerebral Palsy yang Terhimpun dalam Group Facebook Orang Tua Anak Cerebral Palsy. Pascasarjana, Yogyakarta: Universitas Islam Negeri Sunan Kalijaga.

Wawan, A dan Dewi (2011) Teori dan Pengukuran Pengetabuan, Sikap, dan Perilaku Manusia, Yogyakarta: Nuha Medika. 